\title{
Inhibition of activated STAT5 in Bcr/Abl expressing leukemia cells with new pimozide derivatives
}

\author{
Riccardo Rondanin $^{\mathrm{a}, *}$, Daniele Simoni ${ }^{\mathrm{a}}$, Romeo Romagnoli ${ }^{\mathrm{a}}$, Riccardo Baruchello ${ }^{\mathrm{a}}$, Paolo Marchetti ${ }^{\mathrm{a}}$, \\ Cristiana Costantini ${ }^{a}$, Sara Fochi ${ }^{\mathrm{a}}$, Giacomo Padroni ${ }^{\mathrm{a}}$, Stefania Grimaudo ${ }^{\mathrm{b}}$, Rosaria Maria Pipitone ${ }^{\mathrm{b}}$, \\ Maria Meli ${ }^{\mathrm{c}}$, Manlio Tolomeo ${ }^{\mathrm{d}}$ \\ ${ }^{a}$ Dipartimento di Scienze Chimiche e Farmaceutiche, Università di Ferrara, via Fossato di Mortara 17, I-44121 Ferrara, Italy \\ ${ }^{\mathrm{b}}$ Dipartimento Biomedico di Medicina Interna e Specialistica, Università di Palermo, Palermo, Italy \\ ${ }^{\mathrm{c}}$ Dipartimento di Scienze per la Promozione della Salute e Materno Infantile, Area di Farmacologia, Università di Palermo, Palermo, Italy \\ ${ }^{\mathrm{d}}$ Centro Interdipartimentale di Ricerca in Oncologia Clinica e Dipartimento Biomedico di Medicina Interna e Specialistica, Sezione di Malattie Infettive, Università di Palermo, \\ Palermo, Italy
}

\section{A R T I C L E I N F O}

\section{Article history:}

Received 11 July 2014

Accepted 25 July 2014

Available online 1 August 2014

\section{Keywords:}

STAT5 inhibitors

Pimozide

BCR/ABL expressing leukemia

Apoptosis

Cell growth inhibition

\begin{abstract}
A B S T R A C T
STATs are transcription factors acting as intracellular signaling after stimulation with cytokines, growth factors and hormones. STAT5 is also constitutively active in many forms of cancers, including chronic myelogenous leukemia, acute lymphoblastic leukemia and Hodgkin's lymphoma. Recently, literature reported that the neuroleptic drug pimozide inhibits STAT5 phosphorylation inducing apoptosis in CML cells. We undertook an investigation from pimozide structure, obtaining simple derivatives with cytotoxic and STAT5-inhibitory activity, two of them markedly more potent than pimozide.
\end{abstract}

(c) 2014 Elsevier Ltd. All rights reserved.
Signal transducers and activators of transcription (STATs) are transcription factors that act as intracellular signaling after stimulation with cytokines, growth factors and hormones. STATs are activated into the cytosol by phosphorylation of specific tyrosine residues forming homo- or heterodimers that enter into the nucleus and bind to the specific DNA sequences in the promoter regions of various genes involved in cell survival, proliferation and differentiation.

STAT5 protein consists of a N-terminal domain that is involved in promoting STAT5 dimerization, a DNA binding domain that interacts with a conserved DNA binding sequence, an SH2 domain that drives the initial interaction of STAT5 protein with phosphorylated tyrosine residues in the cytoplasmic tails of cytokine receptors, and a C-terminal transactivation domain. ${ }^{2}$

In order to be functional, STAT5 proteins must first be activated. This activation is carried out by kinases associated with transmembrane receptors. Firstly, ligands (cytokines, growth factors) binding to these transmembrane receptors on the outside of the cell activate JAK2 (Janus kinase 2) which in turn add a phosphate group to a specific tyrosine residue on the receptor; STAT5 then binds

\footnotetext{
* Corresponding author. Tel.: +390532 455384.

E-mail address: rnd@unife.it (R. Rondanin).
}

to these phosphorylated-tyrosines using their $\mathrm{SH} 2$ domain. The bound STAT5 is then phosphorylated by JAK2 and the phosphorylated STAT5 finally goes on to form either homodimers, STAT5STAT5, or heterodimers, STAT5-STATX, with other STAT proteins.,

The interest of STAT5 in oncology comes from the initial observations of its activation in many malignancies. Epigenetic changes, regulation by miRNA, altered proteolytic pathways, gene amplification and aberrant growth factor signaling contribute to activation of STAT5 proteins in human cancers; however, mutations in STAT5 genes have not been found, with the exception of myeloid leukemia, where the STAT5 C-terminal part fuses with RAR $\alpha$. In contrast, mutations in signaling pathways acting upstream of STAT5 proteins are frequent in many cancer types.

Constitutively STAT5 activation was found in hematological malignancies such as acute lymphocytic leukemia (ALL), erythroleukemia, chronic myelogenous leukemia (CML) and in others myeloproliferative diseases. ${ }^{5}$

Differently from normal cells in which STAT5 is activated by JAK2, in ALL and CML the products of the fusion proteins TEL/ JAK2 and BCR/ABL activate directly STAT5 proteins. Activated STAT5 seems to plays a crucial role in growth and survival of CLM cells suggesting that drugs able to target STAT5 could be useful for the treatment of this type of leukemia, especially for CML resistant to imatinib or other BCR/ABL targeted molecules. ${ }^{6}$ 


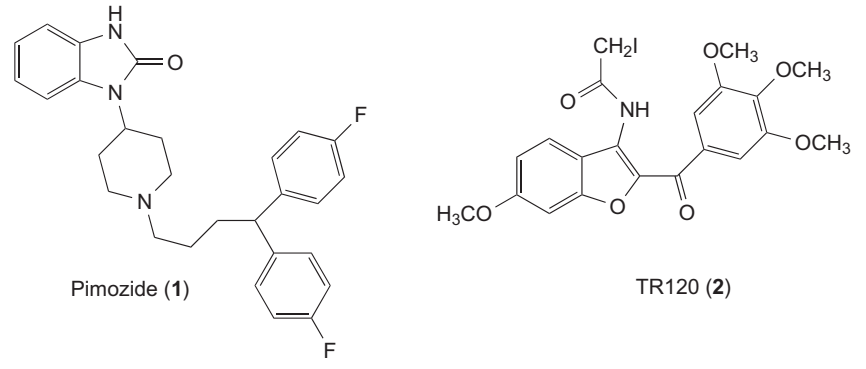

Figure 1. The neuroleptic drug pimozide and compound TR120 inhibit STAT5 phosphorylation.

In recent years, literature reported the synthesis of some structures able to inhibit STAT5, ${ }^{7,8}$ as a novel approach for leukemic therapy. In particular, Nelson et al. undertook a screen to isolate STAT inhibitors that may be useful for cancer therapy. They used a transcriptionally based assay, which provides a nonbiased approach for the identification of inhibitors targeting any part of the STAT-signaling pathway. To accelerate the identification of
Table 1

$\mathrm{IC}_{50}{ }^{\mathrm{a}}(\mu \mathrm{M} \pm \mathrm{SE})$ and $\mathrm{AC}_{50}{ }^{\mathrm{b}}(\mu \mathrm{M} \pm \mathrm{SE})$ of pimozide and analogues evaluated in $\mathrm{K} 562$ cells after $48 \mathrm{~h}$ of treatment

\begin{tabular}{lll}
\hline Compounds & $\mathrm{IC}_{50}(\mu \mathrm{M})$ & $\mathrm{AC}_{50}(\mu \mathrm{M})$ \\
\hline Pimozide (1) & $5 \pm 0.8$ & $10 \pm 2.3$ \\
$\mathbf{3}$ & $>50$ & $>50$ \\
$\mathbf{4}$ & $>50$ & $>50$ \\
$\mathbf{5}$ & $>50$ & $>50$ \\
$\mathbf{6}$ & $>50$ & $>50$ \\
$\mathbf{7}$ & $7.3 \pm 1.2$ & $14 \pm 2.8$ \\
$\mathbf{8}$ & $2.4 \pm 0.5$ & $4.8 \pm 0.6$ \\
$\mathbf{9}$ & $1.8 \pm 0.22$ & $5 \pm 0.7$ \\
$\mathbf{1 0}$ & $>50$ & $>50$ \\
$\mathbf{1 1}$ & $>50$ & $>50$ \\
$\mathbf{1 2}$ & $>50$ & $>50$ \\
$\mathbf{1 3}$ & $>50$ & $>50$ \\
$\mathbf{1 4}$ & $35 \pm 4.4$ & $>50$ \\
$\mathbf{1 5}$ & $>50$ & $>50$ \\
$\mathbf{2 0}$ & $13 \pm 2.1$ & $18 \pm 2.9$ \\
$\mathbf{2 1}$ & $18 \pm 3.6$ & $35 \pm 4.8$ \\
$\mathbf{2 2}$ & $14 \pm 2.8$ & $19 \pm 2$ \\
$\mathbf{2 3}$ & $>50$ & $>50$
\end{tabular}

a Concentration able to inhibit 50\% cell growth.

b Concentration able to induce apoptosis in $50 \%$ of cells.
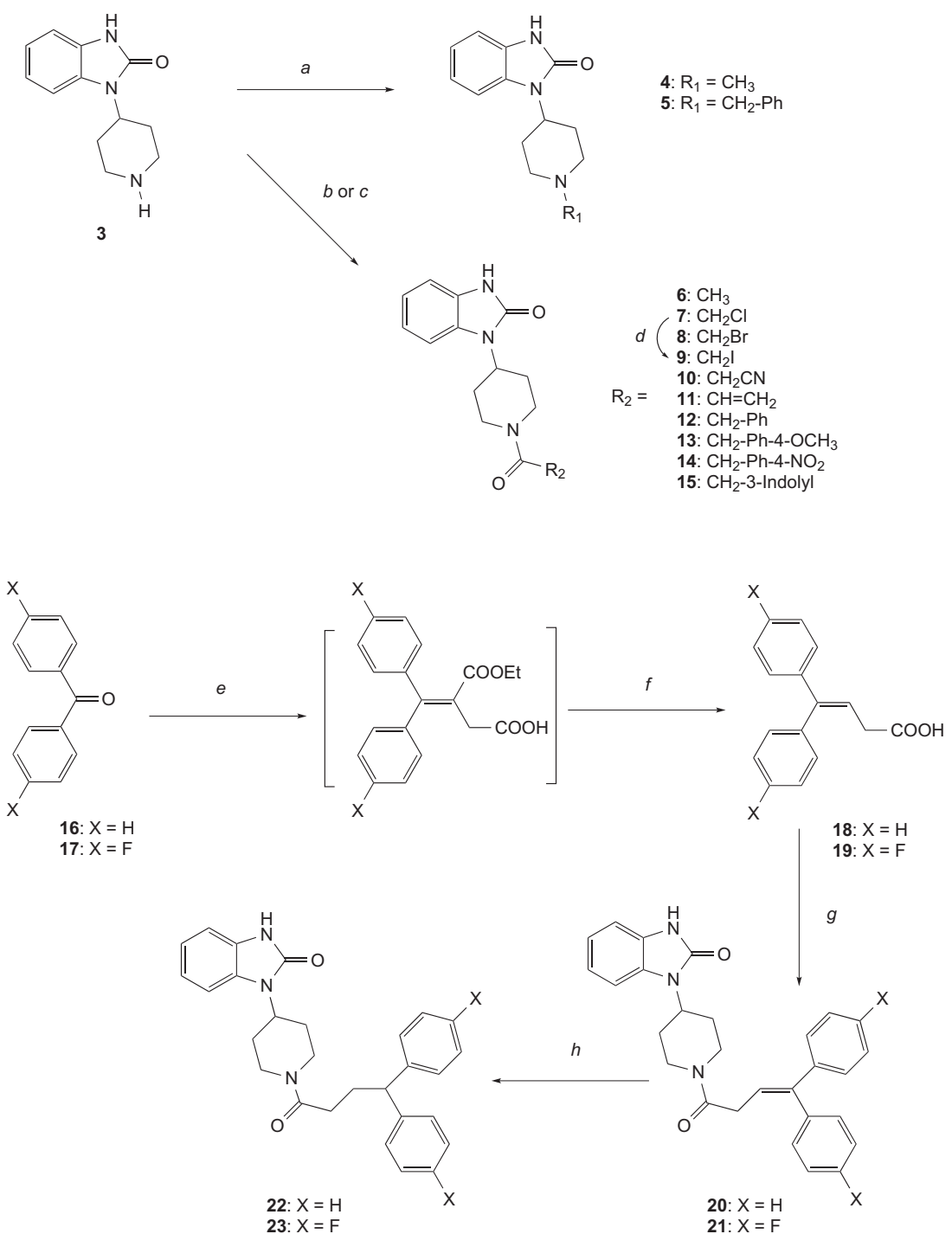

Scheme 1. Reagents and conditions: (a) $\mathrm{CH}_{3} \mathrm{I}$ or Benzyl bromide, $\mathrm{K}_{2} \mathrm{CO}_{3}, \mathrm{CH}_{3} \mathrm{CN} / \mathrm{MeOH}$; (b) $\mathrm{Ac}_{2} \mathrm{O}$ and TEA or acyl halide and pyridine in $\mathrm{CHCl}_{3}$ (for 6-8,11); (c) carboxylic acid, $\mathrm{EDC}, \mathrm{HOBt}, \mathrm{CHCl}_{3}$ (for 10, 12-15); (d) NaI, acetone; (e) diethyl succinate, $t \mathrm{BuOK}, t \mathrm{BuOH}$, reflux; (f) $\mathrm{AcOH} / 48 \% \mathrm{HBr}$ aq, reflux, $36 \mathrm{~h}$; (g) EDC, $\mathrm{HOBt}, \mathrm{CHCl} 3{ }_{3}$; (h) $\mathrm{H}_{2}$, $\mathrm{Pd} / \mathrm{C} 10 \%, \mathrm{EtOH} /$ EtOAc 


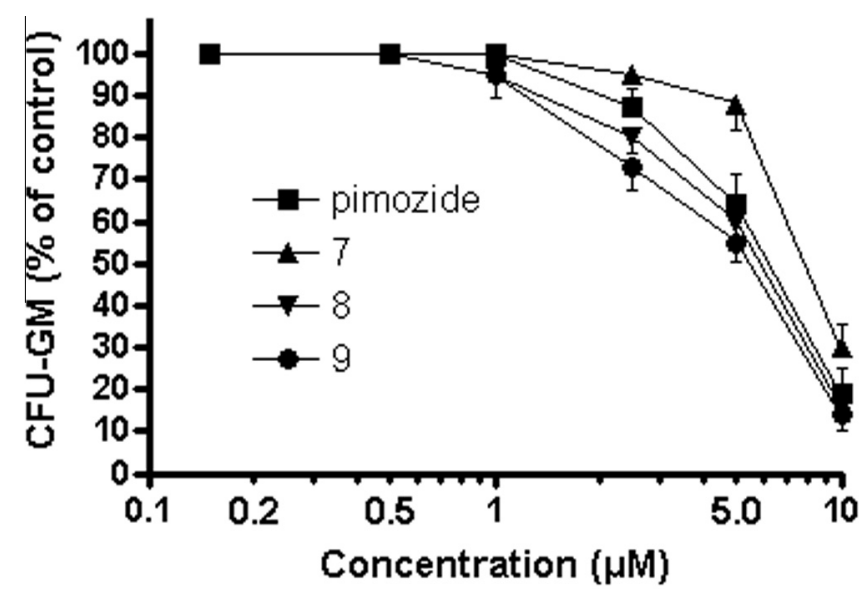

Figure 2. Effects of pimozide and pimozide derivatives 7, 8 and 9 on normal CFU-GM. Cells were exposed to increasing concentrations of each compound. The number of CFU-GM was calculated after 7 days of cell culture. Bars: \pm SE. drugs that could be used in proof-of-concept clinical trials, they used a chemical library that contained compounds known to be safe in humans. ${ }^{9-11}$ These studies have led to identify the neuroleptic drug pimozide (1, Fig. 1) as potent STAT5 inhibitor and potent inductor of apoptosis in CML cells. From literature data, there are evidences that pimozide and other antipsychotic drugs could act as antiproliferative agent through different mechanisms. ${ }^{12-14}$

Pimozide decreased STAT5 tyrosine phosphorylation, although it did not inhibit BCR/ABL or other tyrosine kinases. Moreover, pimozide decreased the expression of STAT5 target genes and induced cell cycle arrest and apoptosis in CML cell lines. Of interest, pimozide induced similar effects in cells expressing T315 BCR/ABL mutation. Simultaneously inhibiting STAT5 with pimozide and the kinase inhibitors imatinib or nilotinib showed enhanced effects in inhibiting STAT5 phosphorylation and in inducing apoptosis.

In our recent efforts to find new antiproliferative molecules, ${ }^{15,16}$ while synthesizing a new class of substituted 2-(3,4,5-trimethoxybenzoyl)-2- $N, N$-dimethylamino-benzo[ $b]$ furans as tubulin
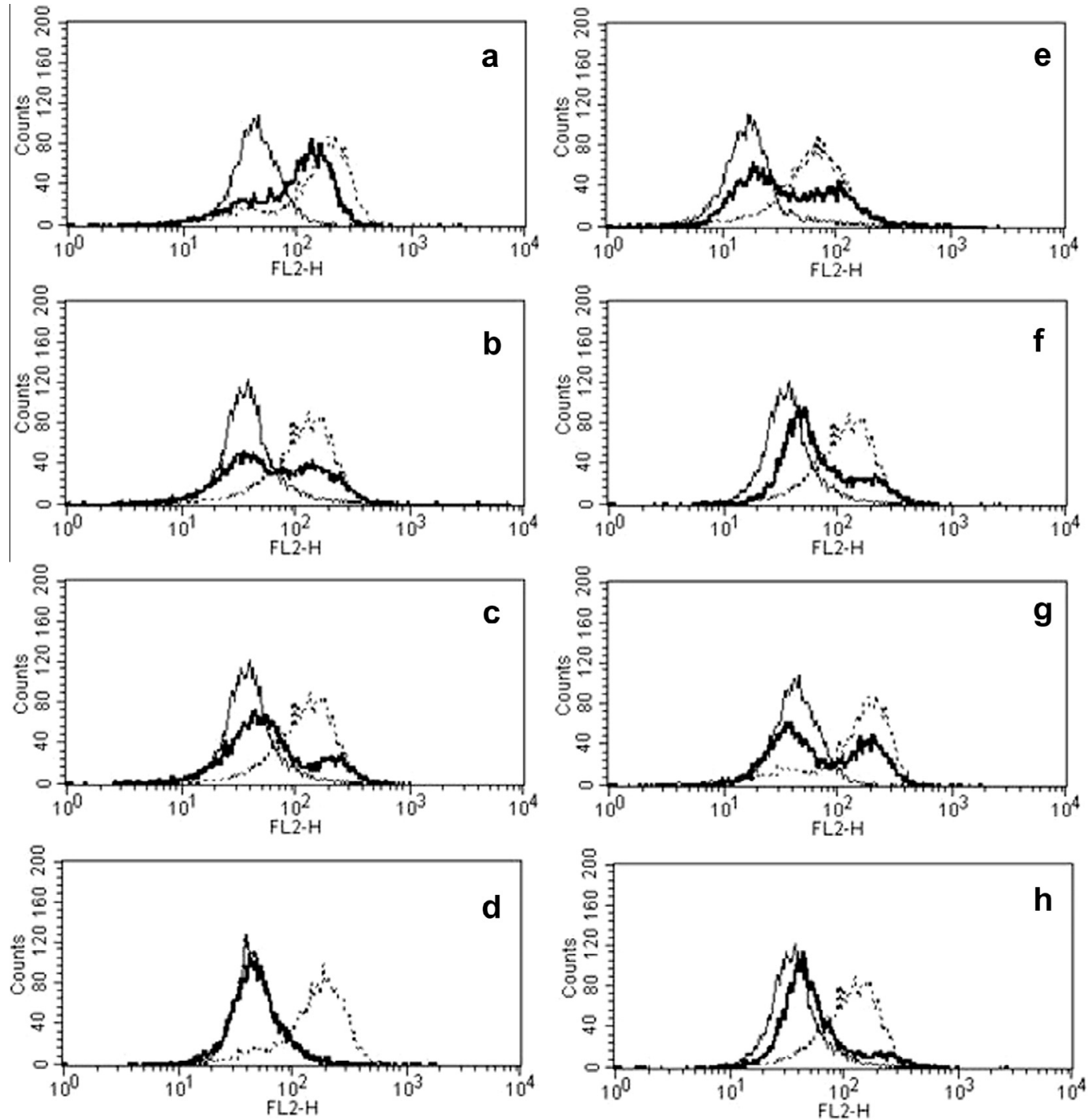

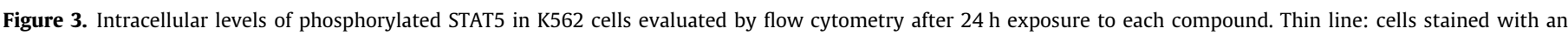

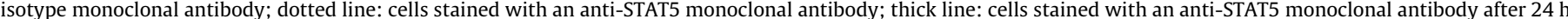

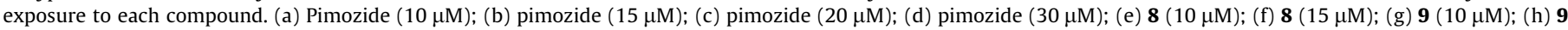
(15 $\mu \mathrm{M})$. 

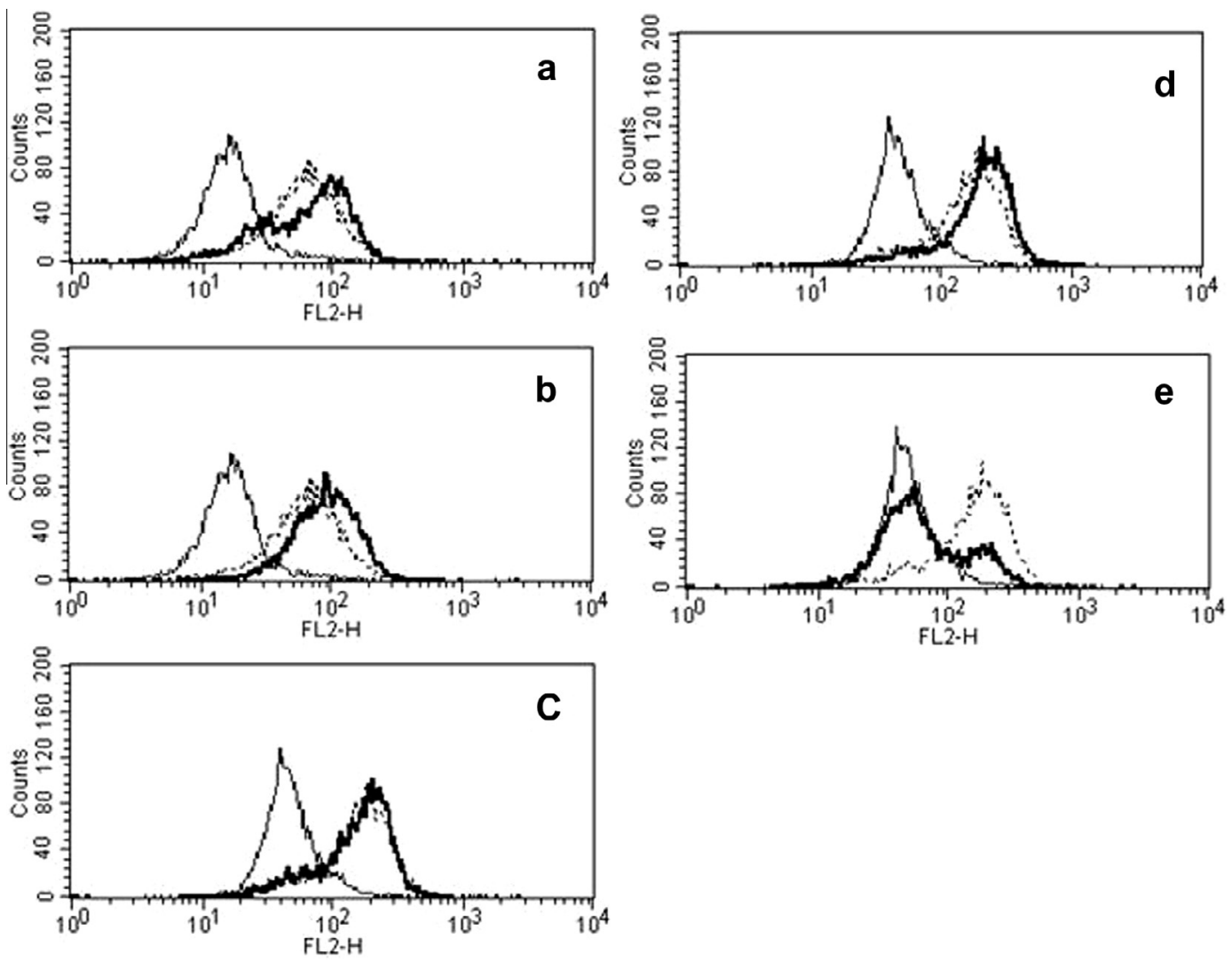

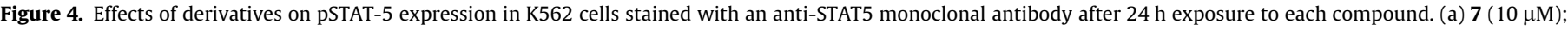
(b) $20(20 \mu \mathrm{M})$; (c) $22(20 \mu \mathrm{M})$; (d) $14(30 \mu \mathrm{M})$; (e) $21(20 \mu \mathrm{M})$.

Table 2

Median fluorescence values of K562 cells stained with an anti-pSTAT5 after $24 \mathrm{~h}$ exposure to pimozide and pimozide analogues

\begin{tabular}{lc}
\hline Compounds & Median fluorescence \\
\hline Control (Isotypic MoAb) & 46.56 \\
Control (pSTAT5 MoAb) & 189.38 \\
Pimozide $(10 \mu \mathrm{M})$ & 118.64 \\
Pimozide $(15 \mu \mathrm{M})$ & 91.15 \\
Pimozide $(20 \mu \mathrm{M})$ & 62.65 \\
Pimozide $(30 \mu \mathrm{M})$ & 46.5 \\
$\mathbf{7}(10 \mu \mathrm{M})$ & 214.87 \\
$\mathbf{8}(10 \mu \mathrm{M})$ & 89.79 \\
$\mathbf{8}(15 \mu \mathrm{M})$ & 71.00 \\
$\mathbf{9}(10 \mu \mathrm{M})$ & 60.96 \\
$\mathbf{9}(15 \mu \mathrm{M})$ & 60.04 \\
$\mathbf{1 4}(30 \mu \mathrm{M})$ & 220.69 \\
$\mathbf{2 0}(20 \mu \mathrm{M})$ & 261.89 \\
$\mathbf{2 1}(20 \mu \mathrm{M})$ & 54.25 \\
$\mathbf{2 2}(20 \mu \mathrm{M})$ & 177.84 \\
\hline
\end{tabular}

Control (Isotypic MoAb) = K562 cells stained with an isotypic MoAb. Control (STAT5 $\mathrm{MoAb})=\mathrm{K} 562$ cells stained with an STAT5 MoAb.

inhibitors, we found that the 3-iodoacetylamino-6-methoxybenzofuran-2-yl(3,4,5-trimethoxyphenyl)methanone (TR120, 2) showed a marked cytotoxic activity in imatinib-resistant BCR/ ABL expressing leukemia cells by inducing a marked decrease in STAT5 phosphorylated expression. ${ }^{17}$ Of interest, TR120 determined synergistic effects when used in combination with imatinib in both sensitive and resistant cells.

Taking advantage from this experience, with the aim to obtain potent STAT5 inhibitors able to interfere with BCR/ABL expressing leukemia cells growth, we decided to investigate structural alterations of pimozide, trying to improve its STAT5 inhibitory activity and, at the same time, avoiding its CNS side effects. Both the cytotoxicity and drug influence on the intracellular levels of phosphorylated STAT5 in the BCR/ABL positive K562 leukemia cell line were determined for all new synthesized derivatives. We observed that some derivatives were endowed with cytotoxic and STAT5-inhibitory activity and two of them were markedly more potent than pimozide.

The benzimidazolinone-piperidine group is frequently seen in differently targeted active compounds other than pimozide, ${ }^{18-20}$ representing an important privileged structure for biological activities. Therefore, in our investigation, we chose the benzimidazolinone-piperidine portion of pimozide as a steady point.

Alkyl or acyl groups were then bound to the piperidine nitrogen of 3, in order to achieve information about its importance for the STAT5 inhibition properties. We obtained acetic (halogenated, -cyano, or -phenyl) or acrylic derivatives. The haloacetic appendages were chosen with regard of our previous promising results obtained from TR120. Moreover, we searched for additional information from smaller modifications of pimozide structure, by changing the piperidine nitrogen substitution from the original 4,4-di(p-fluorophenyl)butyl chain into analogue 4,4-diarylbutanoyl groups. In this case, we were interested in understanding whether by switching this simple amine into an amide functional group it could be possible to maintain STAT5 inhibition but to lose the CNS effects of pimozide. This strategy allowed us to explore the activity of a small library of compounds, either very similar to pimozide, or with smaller structures.

Derivatives were synthesized starting from a commercial intermediate (3, Scheme 1$)$ alkylated or acylated at piperidine nitrogen. Simple methyl and benzyl compounds have been obtained from 3 and equimolar methyl iodide or benzyl bromide in mixed acetonitrile/methanol solution and excess potassium carbonate. Most of 

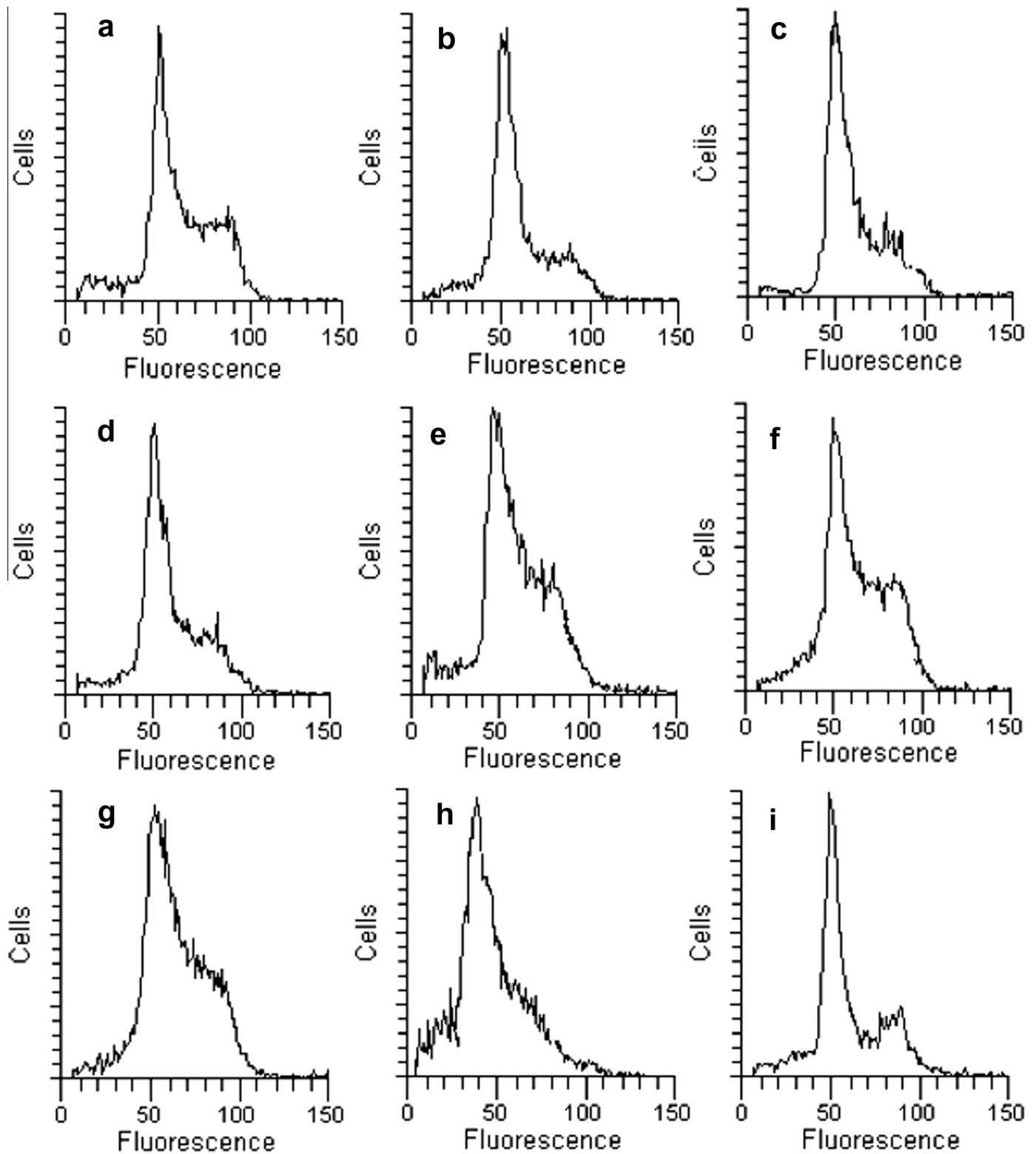

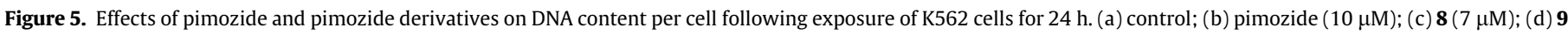
(5 $\mu \mathrm{M})$; (e) $7(10 \mu \mathrm{M})$; (f) $20(20 \mu \mathrm{M})$; (g) $14(40 \mu \mathrm{M})$; (h) $21(30 \mu \mathrm{M})$; (i) $22(30 \mu \mathrm{M})$.

acyl derivatives have been obtained from commercial acyl halides or from carboxylic acids via carbodiimide activation. Iodoacetyl derivative (9) was obtained by halogen exchange from chloroacetyl compound (7) with sodium iodide in acetone. Unsaturated acid intermediates to obtain compounds $\mathbf{2 0 , 2 1}$ were prepared adapting a procedure reported in literature, ${ }^{21}$ starting from commercial benzophenones 16,17 , reacted with diethyl succinate in the presence of potassium tert-butoxide/tert-butyl alcohol; the intermediates were then decarboxylated by refluxing in $1: 148 \%$ aqueous $\mathrm{HBr} /$ acetic acid for $36 \mathrm{~h}$ to obtain acids $\mathbf{1 8 , 1 9}$. Reduction with $\mathrm{H}_{2}$ and $10 \% \mathrm{Pd} / \mathrm{C}$ of amides $\mathbf{2 0 , 2 1}$ gave derivatives $\mathbf{2 2 , 2 3}$.

Table 1 shows the cytotoxic effects evaluated as IC $_{50}$ (concentration able to inhibit $50 \%$ cell growth) and $\mathrm{AC}_{50}$ (concentration able to induce apoptosis in $50 \%$ of cells) of pimozide and pimozide analogues in $\mathrm{K} 562$ cells exposed $48 \mathrm{~h}$ to each compound. Compounds $3,4,5,6,10,11,12,13,15$ and 23 did not show important cytotoxic effects on $\mathrm{K} 562$ cells showing an $\mathrm{IC}_{50}$ higher than $50 \mu \mathrm{M}$. Compounds 7, 20, 21 and 22 showed an $\mathrm{IC}_{50}$ ranging from $7.3 \mu \mathrm{M}$ and $18 \mu \mathrm{M}$, and an $\mathrm{AC}_{50}$ from $14 \mu \mathrm{M}$ and $35 \mu \mathrm{M}$; therefore, these compounds were slightly less cytotoxic than pimozide $\left(\mathrm{IC}_{50}\right.$ $\left.5 \mu \mathrm{M} ; \mathrm{AC}_{50} 10 \mu \mathrm{M}\right)$. Compound 14 was endowed with low cytotoxicity $\left(\mathrm{IC}_{50} 35 \mu \mathrm{M} ; \mathrm{AC}_{50}>50 \mu \mathrm{M}\right)$. Finally compounds 8 and 9 were more active than pimozide.

In order to evaluate the toxicity of the most active pimozide derivatives (compounds 7, 8 and 9) on non-transformed cells, a clonal assay for CFU-GM (colony-forming units-granulocyte macrophage) was performed on bone marrow mononucleated cells obtained from bone marrow aspirates of three normal volunteers. As shown in Figure 2 the effects of compounds 7, 8 and $\mathbf{9}$ on CFU-GM were similar to those displayed by pimozide.

Analysis of pSTAT5 expression was carried out by flow cytometry after staining cells with a fluorochrome-conjugated monoclonal antibody anti-pSTAT5. In Figures 3 and 4 the curves expressing the fluorescence of cells stained with a fluoresceinated anti-pSTAT5 after $24 \mathrm{~h}$ exposure to each compound (thick lines) were compared to those expressing the fluorescence of untreated cells stained with 
Table 3

Cell cycle distribution (\%) of K562 cells after $24 \mathrm{~h}$ exposure to pimozide and pimozide derivatives

\begin{tabular}{lllc}
\hline Compound & $\mathrm{G}_{1}(\%)$ & $\mathrm{S}(\%)$ & $\mathrm{G}_{2}-\mathrm{M}(\%)$ \\
\hline Control & 39.05 & 45.94 & 15.01 \\
Pimozide (1) & 51.28 & 38.41 & 10.31 \\
$\mathbf{7}$ & 33.67 & 60.23 & 6.1 \\
$\mathbf{8}$ & 47.55 & 43.23 & 9.22 \\
$\mathbf{9}$ & 46.96 & 39.06 & 13.98 \\
$\mathbf{1 4}$ & 31.72 & 62.21 & 6.07 \\
$\mathbf{2 0}$ & 34.1 & 58.57 & 7.33 \\
$\mathbf{2 1}$ & 47.2 & 46.64 & 6.16 \\
$\mathbf{2 2}$ & 48.02 & 31.57 & 20.41 \\
\hline
\end{tabular}

an anti-pSTAT5 (dotted lines) and to those stained with an isotype monoclonal antibody. The concentrations of each compound used for pSTAT5 analysis were scarcely or not cytotoxic on K562 at $24 \mathrm{~h}$.

As shown in Figure 3, pimozide was able to decrease the expression of pSTAT5 in a dose dependent manner. However, compounds $\mathbf{8}$ and $\mathbf{9}$ were more effective than pimozide to reduce the level of pSTAT5 when used at concentrations of $10 \mu \mathrm{M}$ and $15 \mu \mathrm{M}$ (Fig. 3, panels a, b, e, f, g, h, and Table 2). Compounds 7, 14, 20, 22, were ineffective causing, in contrast to $\mathbf{8}$ and $\mathbf{9}$, a slight increase in pSTAT5 levels (Fig. 4, Table 2).

Of interest, compound $\mathbf{2 1}$ showed an inhibitory activity on pSTAT5 similar to that of pimozide (Fig. 3 panel c and Fig. 4 panel e, Table 2).

Cell cycle analysis (Fig. 5 and Table 3 ) revealed that compounds able to induce a decrease in pSTAT5 expression, such as pimozide, 8,9 and 21 caused a prevalent block in $G_{1}$; in contrast, compounds inactive on pSTAT5 induced an arrest of cells in $S$ phase, with the exception of compound $\mathbf{2 2}$ that blocked cells in $\mathrm{G}_{1}$ without effects on PSTAT5. These data are in line with our previous observations ${ }^{17}$ and with the function of STAT5 to promote cell cycle progression.

In our study, pimozide was effective in reducing intracellular pSTAT5 expression showing the maximum effect at the concentration of $30 \mu \mathrm{M}$. Moreover pimozide was endowed with cytotoxic activity on K562 cells. However, our compounds 8 and 9 were more active than pimozide either as cytotoxic agents or pSTAT5 inhibitors. In fact, 9 was $2.7,2.0$, and 1.49 times more potent than pimozide as cytotoxic, apoptotic and pSTAT5 inhibitor agent respectively. Compound $\mathbf{8}$ was slightly less potent than $\mathbf{9}$. Of interest, compound $\mathbf{2 1}$ was less cytotoxic than pimozide but shows a pSTAT5 inhibitory activity slightly higher than pimozide. All these compounds, included pimozide, caused a block in $G_{1}$ phase of cell cycle.

Anticonvulsive and antipsychotic drugs can induce blood dyscrasias. $^{22}$ Toxic suppression of hematopoietic precursors by prolonged administration has been observed after the use of phenothiazines. Also new atypical neuroleptic drugs can induce toxic suppression of hematopoietic precursors. ${ }^{23}$ Pimozide is an antipsychotic drug of the diphenylbutylpiperidine class. It has not been shown to have important adverse effects on normal hematopoietic cells. In fact, while pimozide can decrease colony formation of bone marrow progenitor cells derived from patients with CML, it has almost no effect on hematopoietic progenitors derived from healthy donors. ${ }^{9}$

Our most active pimozide derivatives 7, 8 and 9 showed on normal hemopoietic cells effects similar to those displayed by pimozide.

The most active derivatives seem to underline the importance of a structural characteristic evidenced in previous results regarding TR120. Indeed, the haloacetamide group represents the most promising appendage with a clear trend of activity $\mathrm{I}>\mathrm{Br}>\mathrm{Cl}$, both as cytotoxic and pSTAT inhibitors.
Although it might trace back to a general alkylating property, the evidenced inhibition of PSTAT5 suggests that a more specific mechanisms seem to be involved in the cytotoxic activity. On the other hand, the introduction of 4,4-diaryl butyryl appendage, apparently much more similar to parent pimozide, gave substantially controversial results. Compounds 20-22 show less cytotoxic and apoptotic potency than pimozide, whereas $\mathbf{2 3}$ is not active. Moreover, only 21 retain a good inhibition of pSTAT5, instead of the slightly more cytotoxic non fluorinated analogues $\mathbf{2 0}$ and $\mathbf{2 2}$. It is still not known how pimozide might lead to the observed high inhibition of STAT5 phosphorylation. Reported results are just excluding a direct inhibition of different STAT5 activator kinases, such as FLT3 ITD transformed in AML, mutated BCR/ABL in CML, and various JAK subtypes. ${ }^{9-11}$ The particular structure-activity relationship of compounds $\mathbf{2 0 - 2 3}$ suggests a finely tuned interaction with the biological counterpart(s). Finally, simple alkyl, $N$-methyl (4) or -benzyl (5), appendages were found of no interest.

In summary, a series of pimozide analogues have been synthesized in order to find new growth inhibitors of BCR/ABL expressing leukemia cell lines without the neuroleptic side effects of parent compound. Simple modifications regarding the 4,4-di(p-fluorophenyl)butyl portion led to the discovery of two haloacetyl derivatives more potent of pimozide, both as cytotoxic and pSTAT5 inhibitors. Other compounds, more similar to pimozide, bearing 4,4-diarylbut-3-enoyl or 4,4-diarylbutanoyl groups, appeared less active, but only one demonstrated a concomitant pSTAT5 inhibitory activity. The presented results demonstrated for the first time that a series of simple derivatives of pimozide maintain a similar or better behavior toward BCR/ABL expressing leukemia cell lines and can be seen as a starting point for the development of a novel class of cancer cells growth inhibitors.

\section{Acknowledgment}

This work was financially supported in part by Ministero dell'Università e della Ricerca Scientifica e Tecnologica (PRIN 2009).

\section{Supplementary data}

Supplementary data (details for the synthesis and spectroscopic characterization of target compounds; evaluation of cytotoxicity, apoptosis, clonal assay for CFU-GM and of intracellular proteins) associated with this article can be found, in the online version, at http://dx.doi.org/10.1016/j.bmcl.2014.07.069.

\section{References and notes}

1. Rane, S. G.; Reddy, E. P. Oncogene 2002, 21, 3334.

2. Buitenhuis, M.; Coffer, P. J.; Koenderman, L. Int. J. Biochem. Cell Biol. 2004, 36, 2120 .

3. Ihle, J. N. Curr. Opin. Cell Biol. 2001, 13, 211.

4. Levy, D. E.; Darnell, J. E., Jr. Nat. Rev. Mol. Cell Biol. 2002, 3, 651.

5. Hoelbl, A.; Schuster, C.; Kovacic, B.; Zhu, B.; Wickre, M.; Hoelzl, M. A.; Fajmann, S.; Grebien, F.; Warsch, W.; Stengl, G.; Hennighausen, L.; Poli, V.; Beug, H.; Moriggl, R.; Sexl, V. EMBO Mol. Med. 2010, 2, 98.

6. Warsch, W.; Walz, C.; Sexl, V. Blood 2013, 122, 2167.

7. Müller, J.; Sperl, B.; Reindl, W.; Kiessling, A.; Berg, T. ChemBioChem 2008, 9, 723.

8. Page, B. D. G.; Khoury, H.; Laister, R. C.; Fletcher, S.; Vellozo, M.; Manzoli, A.; Yue, P.; Turkson, J.; Minden, M. D.; Gunning, P. T. J. Med. Chem. 2012, 55, 1047.

9. Nelson, E. A.; Walker, S. R.; Weisberg, E.; Bar-Natan, M.; Barrett, R.; Gashin, L B.; Terrell, S.; Klitgaard, J. L.; Santo, L.; Addorio, M. R.; Ebert, B. L.; Griffin, J. D.; Frank, D. A. Blood 2011, 117, 3421.

10. Bar-Natan, M.; Nelson, E. A.; Walker, S. R.; Kuang, Y.; Distel, R. J.; Frank, D. A. Leukemia 2012, 26, 1407.

11. Nelson, E. A.; Walker, S. R.; Xiang, M.; Weisberg, E.; Bar-Natan, M.; Barrett, R.; Liu, S.; Kharbanda, S.; Christie, A. L.; Nicolais, M.; Griffin, J. D.; Stone, R. M.; Kung, A. L.; Frank, D. A. Genes Cancer 2012, 3, 503

12. Strobl, J. S.; Peterson, V. A. J. Pharmacol. Exp. Ther. 1992, 263, 186.

13. Bertolesi, G. E.; Shi, C.; Elbaum, L.; Jollimore, C.; Rozenberg, G.; Barnes, S.; Kelly, M. E. M. Mol. Pharmacol. 2002, 62, 210. 
14. Wiklund, E. D.; Catts, V. S.; Catts, S. V.; Fong Ng, T.; Whitaker, N. J.; Brown, A. J.; Lutze-Mann, L. H. Int. J. Cancer 2010, 126, 28.

15. Hsu, L.; Durrant, D. E.; Huang, C.; Chi, N.; Baruchello, R.; Rondanin, R.; Rullo, C.; Marchetti, P.; Grisolia, G.; Simoni, D.; Lee, R. M. Inv. New Drugs 2012, 30, 1379.

16. Baruchello, R.; Simoni, D.; Grisolia, G.; Barbato, G.; Marchetti, P.; Rondanin, R. Mangiola, S.; Giannini, G.; Brunetti, T.; Alloatti, D.; Gallo, G.; Ciacci, A.; Vesci, L.; Castorina, M.; Milazzo, F. M.; Cervoni, M. L.; Guglielmi, M. B.; Barbarino, M.; Foderà, R.; Pisano, C.; Cabri, W. J. Med. Chem. 2011, 54, 8592.

17. Grimaudo, S.; Meli, M.; Di Cristina, A.; Ferro, A.; Pipitone, M. R.; Romagnoli, R.; Simoni, D.; Dieli, F.; Tolomeo, M. Anticancer Drugs 2013, 24, 384

18. Palin, R.; Barn, D. R.; Clark, J. K.; Cottney, J. E.; Cowley, P. M.; Crockatt, M.; Evans, L.; Feilden, H.; Goodwin, R. R.; Griekspoor, F.; Grove, S. J. A.; Houghton,
A. K.; Jones, P. S.; Morphy, R. J.; Smith, A. R. C.; Sundaram, H.; Vrolijk, D. Weston, M. A.; Wishart, G.; Wren, P. Bioorg. Med. Chem. Lett. 2005, 15, 589.

19. Flyrén, K.; Bergquist, L. O.; Castro, V. M.; Fotsch, C.; Johansson, L.; St. Jean, D. J. Jr.; Sutin, L.; Williams, M. Bioorg. Med. Chem. Lett. 2007, 17, 3421.

20. Lewis, J. A.; Scott, S. A.; Lavieri, R.; Buck, J. R.; Selvy, P. E.; Stoops, S. L.; Armstrong, M. D.; Brown, H. A.; Lindsley, C. W. Bioorg. Med. Chem. Lett. 2009 $19,1916$.

21. Welch, W. M.; Kraska, A. R.; Sarges, R.; Koe, B. K. J. Med. Chem. 1984, 27, 1508. 22. Heimpel, H. Eur. J. Haematol. 1996, 57, 11.

23. Alvir, J. M.; Lieberman, J. A.; Safferman, A. Z.; Schwimmer, J. L.; Schaaf, J. A. N. Engl. J. Med. 1993, 329, 162. 